\begin{tabular}{|c|c|c|c|}
\hline DE & \multirow{3}{*}{$\begin{array}{l}\text { DE GRUYTER } \\
\text { OPEN }\end{array}$} & $\begin{array}{l}\text { HUNGARIAN JOURNAL OF } \\
\text { INDUSTRY AND CHEMISTRY }\end{array}$ & \multirow[t]{3}{*}{ 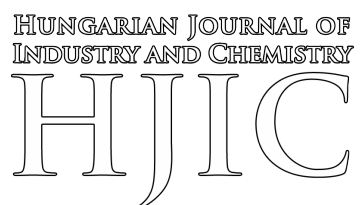 } \\
\hline & & Vol. 43(1) pp. 49-53 (2015) & \\
\hline & & $\begin{array}{l}\text { hjic.mk.uni-pannon.hu } \\
\text { DOI: 10.1515/hjic-2015-0009 }\end{array}$ & \\
\hline
\end{tabular}

\title{
STUDY OF THE INTERFERENCE EFFECTS OF ALUMINIUM ON THE ATOM- AND ION-LINES OF ALKALINE EARTH METALS IN AQUEOUS SOLUTIONS USING AN ICP SPECTROMETER WITH AXIALLY VIEWED PLASMA
}

\author{
OLIVÉR BÁNHIDI \\ Institute of Chemistry, University of Miskolc, Miskolc-Egyetemváros, Miskolc, 3515, HUNGARY
}

The main advantage of inductively coupled plasma spectrometers with axially viewed plasma relative to the radially viewed plasma is the better detection power. The detection limits of the former are about 5-10 times lower than the latter. On the other hand, the axially viewed plasma has disadvantages. The most notable is the increased number of interference effects. In this paper, the study of the interference effects of aluminium on the atom- and ion-lines of alkaline earth metals are presented by examining different types of sample-introduction devices, such as a simple Meinhart-type concentric nebuliser, a V-groove nebuliser using a Sturman-Masters spray chamber, and an ultrasonic nebuliser.

Keywords: aluminium interference effects, ICP atom- and ion-lines, alkaline earth metals, sampleintroduction device, axially viewed plasma

\section{Introduction}

Inductively coupled plasma-atomic emission spectrometry (ICP-AES) is a widely used method for the elementary analysis of different types of material due to its advantageous features. The axial plasma view offers an increased detection power, which is important when the element of interest is present in trace levels. On the other hand, the emitted light is subjected to strong interferences as it reaches the entrance slit of the optical system of the spectrometer. Therefore, it is an important task to understand the origin and nature of the interference effects [1-3].

The interference may affect both the sampleintroduction and excitation processes taking place in the plasma. In the first case, they may have different effects on the different types of sample-introduction devices, while they might affect the atom- and ionlines of a given element in different ways [4].

ICP is commonly used for the analysis of liquid samples, where different types of nebulisers are the most frequently applied devices for sampleintroduction. During nebulisation, the liquids to be analysed are dispersed into small droplets. The difference regarding the different nebulisers lies partially in different processes resulting in small liquid droplets and the nebulisation efficiency. These kinds of effects may be different when different nebulisers are applied, while they appear in the case of both radially and axially viewed plasma.

Correspondence: akmbo@uni-miskolc.hu
The spectral interferences are stronger and more frequent when an axially viewed ICP source is used. This is due to the light being emitted from the hot internal part of the plasma that has to travel a long way to reach the entrance slit of the optical system. On its way, the emitted light goes through layers of plasma at a lower temperature. This process may be subjected to strong self-absorption effects. Consequently, the intensity of the ion- and atom-lines of a given element may change. This change affects the relationship between the emitted line intensity and analyte concentration in the sample, and thus the calibration procedure.

The alkaline earth metals may be present from trace up to high concentration levels in different materials, such as surface and groundwater, different types of rocks and minerals, metal alloys, etc. In many cases, these materials may contain aluminium in high concentrations that contributes to the observation of interferences [2,3]. In the present work, we studied the effect of aluminium on the spectral lines of alkaline earth metals present in lowconcentrations in aqueous solutions, as well as the influence of different sample-introduction devices.

\section{Experimental}

\subsection{ICP Spectrometer}

For the presented experiments, a Varian 720 ES spectrometer was used, which is an axially viewed, instrument with key parameters summarised in Table 1 . 
Table 1. Characteristics of the ICP spectrometer used in the given study.

Plasma-view:
The frequency and power
of the RF generator:
The optical system
employed:
Detector used:
Wavelength range:
Available sample-
introduction systems:

axial

$40 \mathrm{MHz}, 900-1500 \mathrm{~W}$

adjustable via software

Echelle build-up with a

double monochromator

Two-dimension CCD

$160-780 \mathrm{~nm}$

Concentric (K-type)

nebuliser, $\mathrm{V}$-groove

nebuliser, Ultrasonic

nebuliser

Controlling software: $\quad$ ICP Expert II

(Microsoft Win XP OS)

Due to the layout of the optical system, many (even several hundred) spectral lines can be measured simultaneously, which makes the study of the interferences on several atom- and ion-lines of a given element possible. In the course of line selection, care was taken in choosing both more and less sensitive lines, where enough lines were available. The spectral lines examined in this study are summarised in Table 2.

\subsection{The Sample-Introduction Devices}

Three types of sample-introduction device were used in the given set of experiments: a concentric nebuliser, a $\mathrm{V}$-groove nebuliser, and an ultrasonic nebuliser. The concentric nebuliser is the one that is used most commonly for the ICP-AES analysis of liquid samples. Its nebulisation efficiency is rather low, but it can be operated easily, and its maintenance demand is low. Generally, it is used in combination with a cyclone-type glass spray chamber.

The V-groove nebuliser eventually becomes a modified Babington-type nebuliser. It is used with a Sturman-Masters type spray chamber, which has a special plastic surface and is resistant to almost all chemicals including hydrogen fluoride. Its detection power is slightly less than that of the concentric nebuliser, but it has an excellent salt-enduring ability.

The CETAC 5000 type ultrasonic nebuliser boasts a detection power 10 times better than the former two devices. On the other hand, its operation is more difficult and it may be sensitive to higher matrix concentration levels.

\subsection{Samples Used}

The solution samples contained some acid, the alkaline earth analyte elements and aluminium as a matrix component. The matrix element was diluted from a Spectrascan (Teknolab) stock solution containing aluminium at a concentration of $10 \mathrm{~g} \mathrm{dm}^{-3}$. The aluminium concentration in the sample solutions was 0 ,

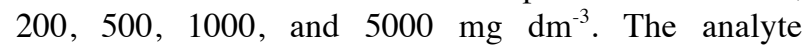
elements were diluted from a multi-element Spectrascan solution of $0.1 \mathrm{~g} \mathrm{dm}^{-3}$. The concentrations of the elements studied were in the range of 0.1 and $10 \mathrm{mg} \mathrm{dm}^{-}$ 3. The solutions contained hydrochloric acid in a concentration of $0.5 \mathrm{~mol} \mathrm{dm}^{-3}$.
Table 2. The spectral lines (wavelength $\lambda$ in $\mathrm{nm}$ and excitation energy $E$ in $\mathrm{eV}$ ) studied.

\begin{tabular}{|c|c|c|c|}
\hline Element & Type of the line & $\lambda$ & $E$ \\
\hline $\mathrm{Be}$ & $\mathrm{Be} \mathrm{I}$ & 234.861 & 5.30 \\
\hline $\mathrm{Be}$ & Be I & 249.473 & 5.01 \\
\hline $\mathrm{Be}$ & Be II & 313.042 & 3.99 \\
\hline $\mathrm{Be}$ & Be II & 313.107 & 3.99 \\
\hline $\mathrm{Mg}$ & Mg I & 285.213 & 4.38 \\
\hline $\mathrm{Mg}$ & Mg I & 383.829 & 3.23 \\
\hline $\mathrm{Mg}$ & $\mathrm{Mg}$ II & 279.553 & 4.47 \\
\hline $\mathrm{Mg}$ & $\mathrm{Mg}$ II & 280.270 & 4.59 \\
\hline $\mathrm{Ca}$ & $\mathrm{Ca} \mathrm{I}$ & 422.673 & 2.96 \\
\hline $\mathrm{Ca}$ & Ca II & 317.933 & 3.93 \\
\hline $\mathrm{Ca}$ & $\mathrm{Ca}$ II & 393.366 & 3.18 \\
\hline $\mathrm{Ca}$ & $\mathrm{Ca}$ II & 396.847 & 3.15 \\
\hline $\mathrm{Sr}$ & Sr I & 460.780 & 2.71 \\
\hline $\mathrm{Sr}$ & $\mathrm{Sr}$ II & 216.596 & 5.76 \\
\hline $\mathrm{Sr}$ & Sr II & 407.771 & 3.07 \\
\hline $\mathrm{Sr}$ & Sr II & 421.552 & 2.96 \\
\hline $\mathrm{Ba}$ & $\mathrm{Ba} \mathrm{I}$ & 705.994 & 1.77 \\
\hline $\mathrm{Ba}$ & Ba II & 233.527 & 5.36 \\
\hline $\mathrm{Ba}$ & Ba II & 455.403 & 2.75 \\
\hline $\mathrm{Ba}$ & $\mathrm{Ba}$ II & 493.408 & 2.53 \\
\hline
\end{tabular}

\subsection{Measurements}

Each of the solutions was measured at a $1050 \mathrm{~W}$ output of high frequency power. The recorded signal intensity was averaged from 3-10 s long replicates. The raw intensities were corrected applying the so-called twoside off-peak background correction method.

In order to easily evaluate the effects, the net intensities measured using sample solutions containing no aluminium were used as reference values, and the net intensity values measured in the presence of aluminium were divided by these reference values. In other words, the evaluation presented here is based upon the relative intensities.

\section{Results}

In the experiments, we studied the intensity changes of several atom- and ion-lines of the alkaline earth metals as a function of aluminium concentration, analyte concentration and that of the device used for sampleintroduction. The results measured using a concentric nebuliser are presented in Figs.1-10. The net intensities obtained using a V-groove nebuliser (Figs.11 and 12) and an ultrasonic nebuliser (Figs.13 and 14) are also presented for the case of calcium ions.

\section{Discussion}

Figs.1-10 show that by using the concentric nebuliser both atomic- and ionic-lines of all alkaline earth metals are affected by aluminium. Nevertheless, substantial differences can be seen depending on the element, type 


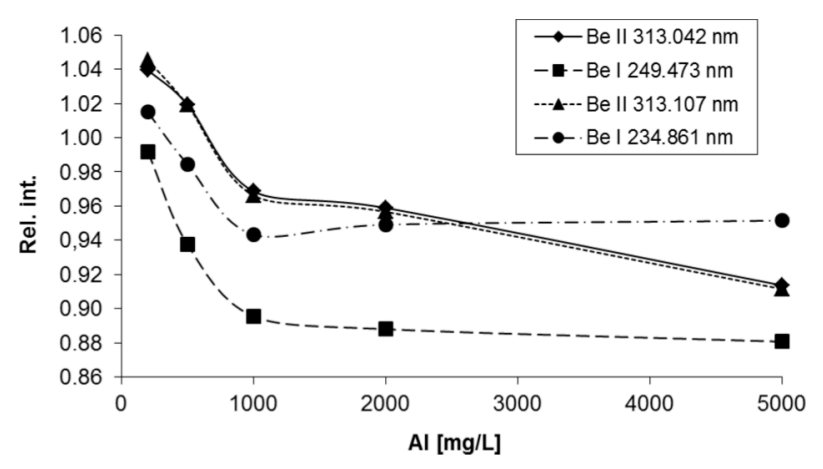

Figure 1. The relative intesities of $0.1 \mathrm{mg} \mathrm{dm}^{-3} \mathrm{Be}$ as a function of $\mathrm{Al}$ concentration, using a concentric nebuliser.

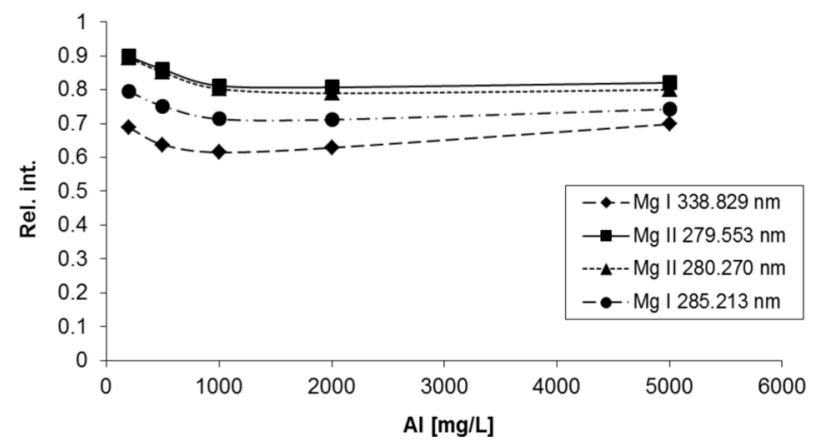

Figure 3. The relative intesities of $0.1 \mathrm{mg} \mathrm{dm}^{-3} \mathrm{Mg}$ as a function of $\mathrm{Al}$ concentration, using a concentric nebuliser.

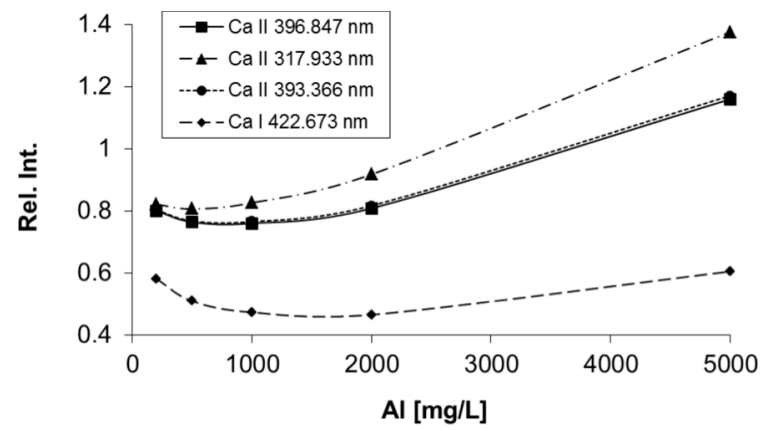

Figure 5. The relative intesities of $0.1 \mathrm{mg} \mathrm{dm}^{-3} \mathrm{Ca}$ as a function of $\mathrm{Al}$ concentration, using a concentric nebuliser.

of spectral line studied, concentration of aluminium, and that of the analyte. At low beryllium concentrations $(0.1$ $\mathrm{mg} \mathrm{dm}{ }^{-3}$ ) the intensities on all lines are heavily affected even at relatively low aluminium concentration (1 $\mathrm{g} \mathrm{dm}^{-3}$ ) levels. Higher aluminium concentrations cause only a moderate reduction in the signal. Similar behaviour can be observed in the case of magnesium, strontium, and barium. As for calcium, the greatest decrease was observed also at an aluminium concentration of $1 \mathrm{~g} \mathrm{dm}^{-3}$, but higher aluminium concentrations cause a smaller decrease, even some increase can be observed in the ion-lines. It can also be observed that atom-lines are usually more strongly affected than ion-lines.

At higher analyte concentrations, the effect of aluminium is greater on all the lines examined and

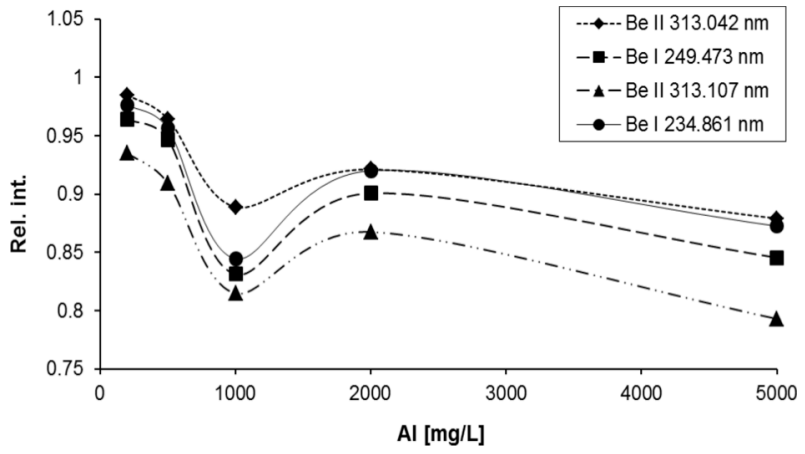

Figure 2. The relative intesities of $10 \mathrm{mg} \mathrm{dm}^{-3} \mathrm{Be}$ as a function of $\mathrm{Al}$ concentration, using a concentric nebuliser.

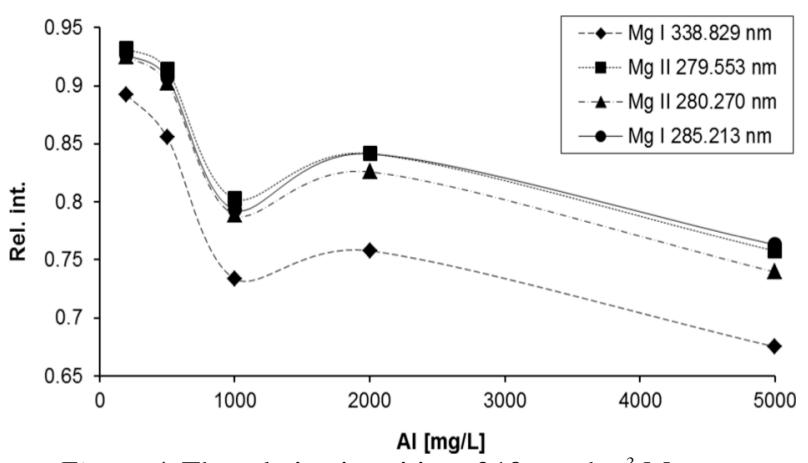

Figure 4. The relative intesities of $10 \mathrm{mg} \mathrm{dm}^{-3} \mathrm{Mg}$ as a function of $\mathrm{Al}$ concentration, using a concentric nebuliser.

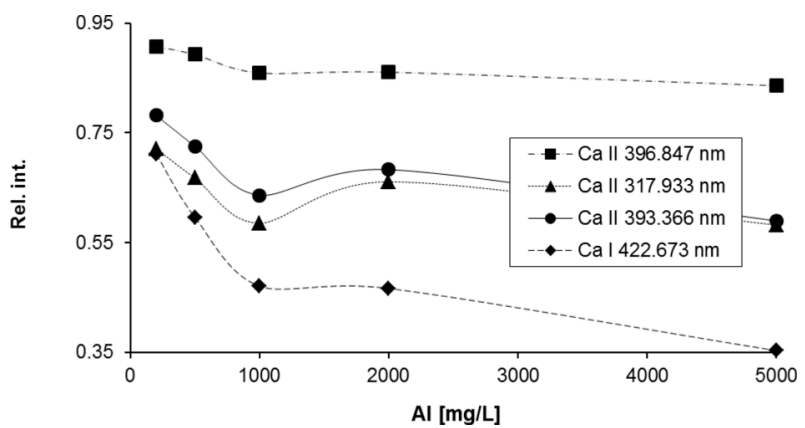

Figure 6. The relative intesities of $10 \mathrm{mg} \mathrm{dm}^{-3} \mathrm{Ca}$ as a function of $\mathrm{Al}$ concentration, using a concentric nebuliser.

increases with increasing aluminium concentration. The only exception is the intensities measured at an aluminium concentration of $1 \mathrm{~g} \mathrm{dm}^{-3}$, where in the case of each analyte the relative intensities are significantly lower than both the values gained at aluminium concentrations of 0.5 and $2 \mathrm{~g} \mathrm{dm}^{-3}$ concentration, though the extent of the effect is different. This effect is larger or even larger in the case of beryllium, magnesium, and barium, and it is less profound for calcium and strontium.

With respect to the different types of lines, in the case of beryllium, where all the lines studied are sensitive, one of the atom-lines $(234.861 \mathrm{~nm})$ is less, while the other $(249.473 \mathrm{~nm})$ is more affected than the ion-lines. One of the atom-lines $(383.829 \mathrm{~nm})$ of magnesium is a weak line, while the other one (285.213 


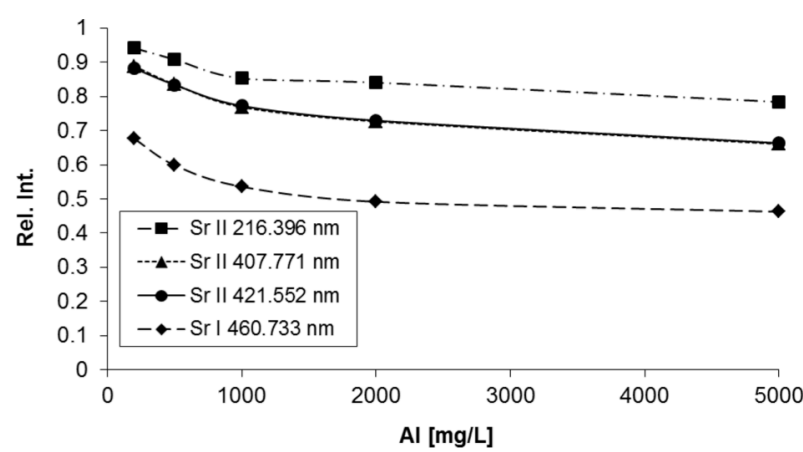

Figure 7. The relative intesities of $0.1 \mathrm{mg} \mathrm{dm}^{-3} \mathrm{Sr}$ as a function of $\mathrm{Al}$ concentration, using a concentric nebuliser.

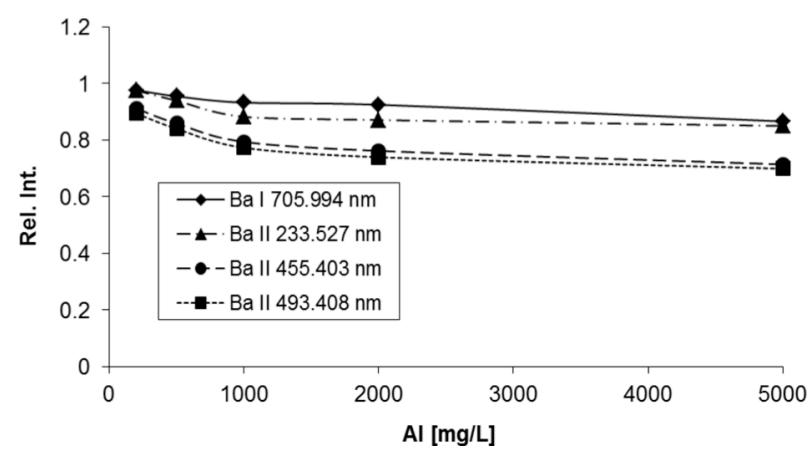

Figure 9. The relative intesities of $0.1 \mathrm{mg} \mathrm{dm}^{-3} \mathrm{Ba}$ as a function of $\mathrm{Al}$ concentration, using a concentric nebuliser.

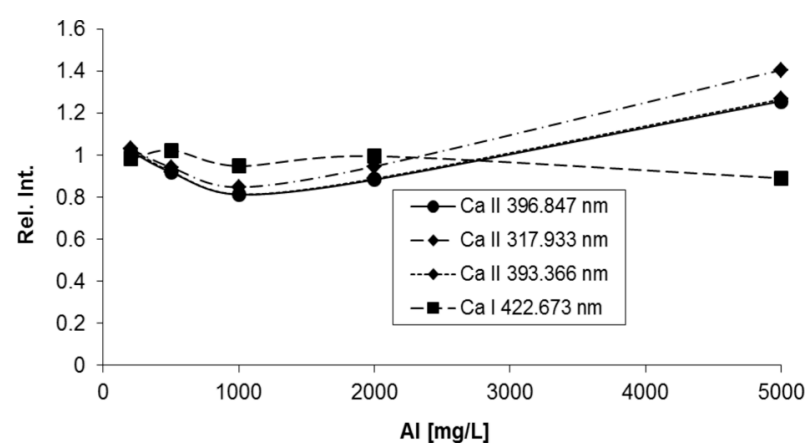

Figure 11. The relative intesities of $0.1 \mathrm{mg} \mathrm{dm}^{-3} \mathrm{Ca}$ as a function of $\mathrm{Al}$ concentration, using a $\mathrm{V}$-groove nebuliser.

$\mathrm{nm})$ is sensitive. The first is heavily affected by aluminium, while the other lines manifest smaller effects. In the case of calcium and strontium, the atomline is much more affected than the ion-lines, while the reverse can be observed for barium. Its atom-line is much less affected than its sensitive ion-lines.

The effect of the sample-introduction devices in Figs.11-14 in the case of calcium manifests that at low analyte concentrations $\left(0.1 \mathrm{mg} \mathrm{dm}^{-3}\right)$ almost the same type of curve is observed with the help of an ultrasonic nebuliser. Using a V-groove type device, only slight effects were detected. At higher analyte concentrations, all the lines are affected using the V-groove nebuliser; while in the case of the ultrasonic device the sensitive ion-lines (393.366 $\mathrm{nm}$ and $396.847 \mathrm{~nm}$ ) are only slightly affected.

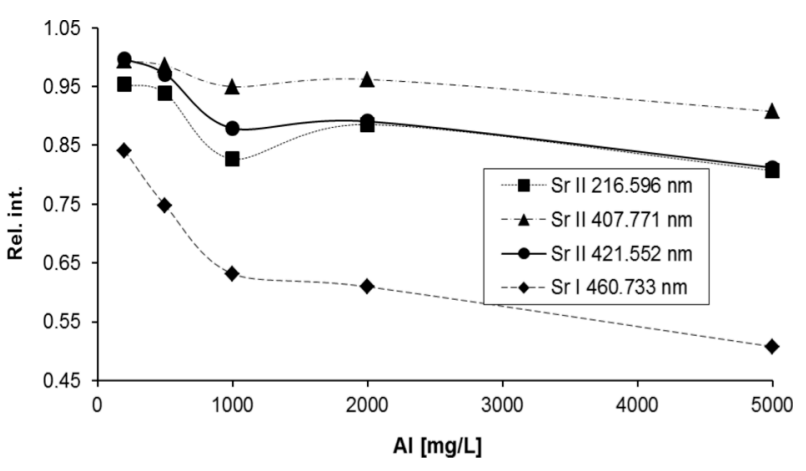

Figure 8. The relative intesities of $10 \mathrm{mg} \mathrm{dm}^{-3} \mathrm{Sr}$ as a function of $\mathrm{Al}$ concentration, using a concentric nebuliser.

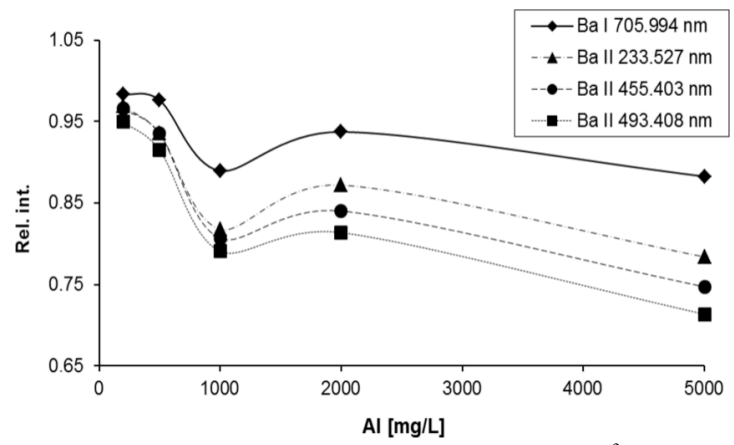

Figure 10. The relative intesities of $10 \mathrm{mg} \mathrm{dm}^{-3} \mathrm{Ba}$ as a function of $\mathrm{Al}$ concentration, using a concentric nebuliser.

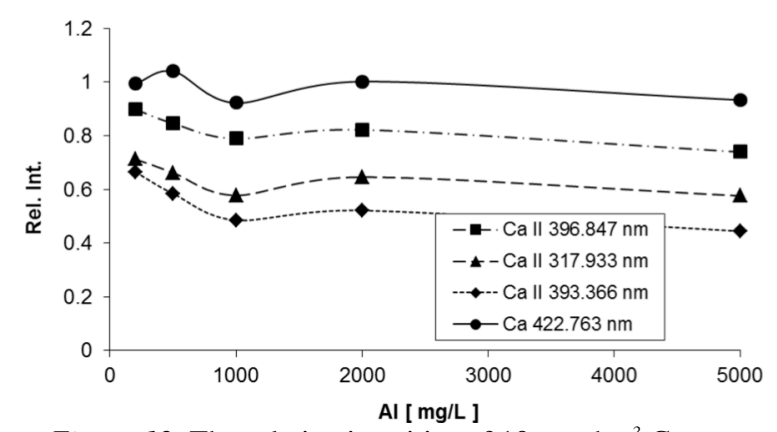

Figure 12. The relative intesities of $10 \mathrm{mg} \mathrm{dm}^{-3} \mathrm{Ca}$ as a function of $\mathrm{Al}$ concentration, using a $\mathrm{V}$-groove nebuliser.

\section{Conclusion}

Using the axially viewed plasma, the light emitted from the high-temperature inner part of the plasma has to pass through the flame to reach the entrance slit of the optical system. As the photons travel, they pass through plasma layers of lower and lower temperatures. In the cooler environment, self-absorption, secondary excitation, and scattering processes can take place. These processes depend on the local temperature, which is also influenced by the high/higher concentration of elements in the sample than the analyte. All these processes make the relationship between line-intensities emitted and analyte concentration rather complicated. 


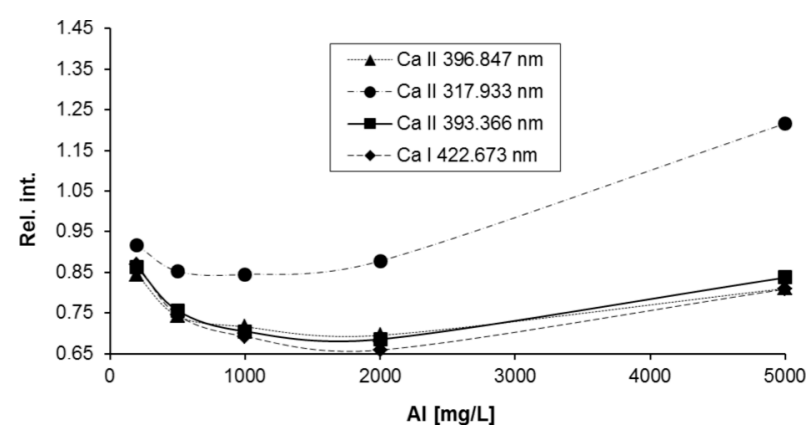

Figure 13. The relative intesities of $0.1 \mathrm{mg} \mathrm{dm}^{-3} \mathrm{Ca}$ as a function of $\mathrm{Al}$ concentration, using an ultrasonic nebuliser.

It can be concluded that aluminium exhibits a strong interference effect on the emitted spectral line intensities of all alkaline earth elements studied. It can also be seen that atom-lines are usually more affected than ion-lines.

Although the relationship between the interferences and line intensities is complicated, in practice it can be eliminated by careful matrixmatching, i.e. the calibration solutions must contain the interfering element (Al) possibly at the same concentration level as the analyte in the samples. In addition, calibration curves can be extended, only with care in the presence of $\mathrm{Al}$, as it could be observed that the extent of the interference is different at low and high analyte concentrations.

\section{Acknowledgement}

This research was supported by the TÁMOP-4.2.1.B10/2/KONV-2010-0001 project and carried out as part of the TÁMOP-4.2.2.A-11/1/KONV-2012-0019 project in the framework of the New Széchenyi Plan. This project was supported by the European Union, and cofinanced by the European Social Fund.

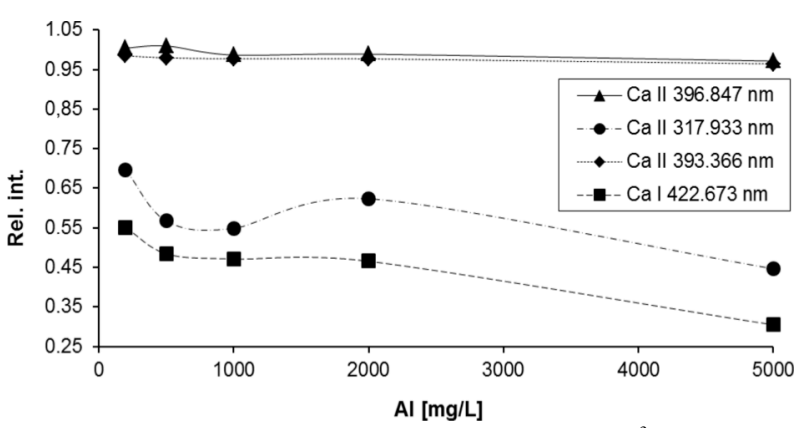

Figure 14. The relative intesities of $10 \mathrm{mg} \mathrm{dm}^{-3}$ calcium as a function of $\mathrm{Al}$ concentration, using an ultrasonic nebuliser.

\section{REFERENCES}

[1] Záray, Gy.: Modern methods of elementary analysis, gas discharge plasmas and their application (University Press, Budapest, Hungary) 2006 (in Hungarian)

[2] Bánhidi, O.: Examination of the interference effects in the course of ICP-AES determination of strontium content of aluminium alloys, Proc. $24^{\text {th }}$ microCAD Conf. (University of Miskolc, Miskolc, Hungary) 2012, Section C

[3] Dubuissan, C.; Pousserl, M.; Mermet, J-M.: Comparison of axially and radially viewed inductively coupled plasma atomic emission spectrometry in terms of signal to background ratio and matrix effects, J. Anal. At. Spect., 1997 12(3), 281-286 10.1039/A606445K

[4] Brenner, I.B.; Zander, A.T.: Axially and radially viewed inductively coupled plasmas - a critical review, Spectrochim. Acta, Part B, 2000 55(8), 1195-1240 10.1016/S0584-8547(00)00243-3 


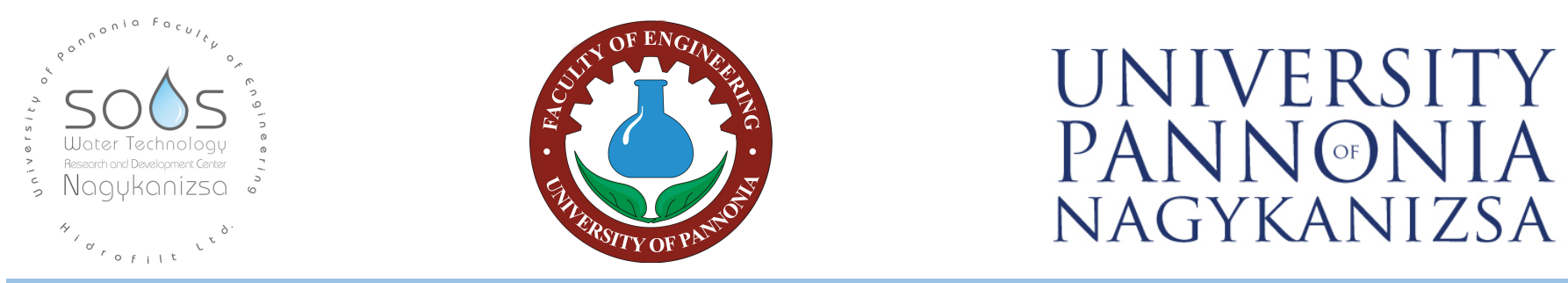

Soós Ernő Water Technology Research and Development Centre was established in 2014 by the Faculty of Engineering at the University of Pannonia, Nagykanizsa Municipality of County Rank and Hidrofilt Water Treatment Ltd. The activities at the Research Centre are built on decades of experience and expertise gained in Nagykanizsa in the field of water treatment and water purification. The goal of the Centre is to perform international-level research activities in different areas of water purification and treatment. Nagykanizsa aims to become a centre of knowledge in national and international relations as well. Besides the fundamental research, the Research Centre plays an active role in industrial development activities, putting a great emphasis on drinking water treatment, power plants, the water management of cooling towers, horticulture and irrigation water treatment, seawater desalination, pharmaceutical and infusion solutions, water supply technologies and related control procedures, and areas of measurement technology.

The areas utilising the development results include:

- Treatment methods for drinking and process water,

- Purified water, ultra pure water, and the pre-treatment of water for the injection of pharmaceuticals,

- Water treatment for horticulture and irrigation,

- Wastewater treatment in the oil and gas industries,

- Grey-water recycling,

- Seawater and brackish desalination,

- Water treatment for swimming pools,

- Monitoring and the control of water treatment, and development of instrumentation.

The Soós Ernő Research Centre is named after a pioneer in the water treatment field who was a chemical and environmental engineer. He made great contributions to the field with his innovative thinking. Several patents in water treatment are tied to his name. The desire of the research team is to advance his work by drawing on his leadership and scientific work as new frontiers in water treatment are pursued.

As an initiative of this decision, the Research Centre organised its first scientific conference in December 2014, entitled Water and Wastewater Treatment in Industry. Nearly 50 presenters attended the conference from both industry and academia with about 170 participants. Based on unanimous support, this conference has become international. In addition to industry and academia, companies from the service sector are also invited. The conference will be held on 28th October 2015, and will be preceded by a project partner meeting.

At the conference, the winners of the Soós Ernö Young Researchers Award will also be announced. This award is a scientific grant for MSc and $\mathrm{PhD}$ candidates. The candidates are invited to submit their theses for nomination from the field of water and wastewater treatment and related disciplines.

The University of Pannonia has a long tradition of academic excellence based on the training of engineering specialists for industry and the economy. The Faculty of Engineering and the Nagykanizsa Campus of the University of Pannonia are committed to forging close and productive partnerships with industry. The water and wastewater treatment system operation programme is designed for engineering and non-engineering graduates who are interested in pursuing a career within companies and organisations involved in water and wastewater treatment.

High-quality academic education is offered together with hands-on training. By participating in the study programme, state-of-the-art knowledge compatible with the current needs of industries and the most advanced water purification technologies applied are acquired. 